\title{
COกE)-(OES
}

CIÊNCIA E TECNOLOGIA

\section{O SABER DOCENTE DO CONHECIMENTO: REFLEXÕES DE UM CURSO DE FORMAÇÃO CONTINUADA COM PROFESSORAS DO ENSINO FUNDAMENTAL I}

\author{
Marcia Borin da Cunha, Olga Maria Schimidt RitTer, \\ ROSANA FRANZEN LEITE \\ Unioeste - Universidade Estadual do Oeste do Paraná \\ <borin.unioeste@gmail.com>.<olga.unioeste@gmail.com>. \\ $<$ rosana.leite@unioeste.br> \\ DOI: <https://doi.org/10.21439/conexoes.v14i4.1585>
}

\begin{abstract}
Resumo. Os saberes da docência precisam ser mobilizados no curso de formação inicial, à medida que se constrói a identidade dos futuros professores. Neste artigo trazemos discussões referentes aos saberes docente do conhecimento, saber esse que se refere ao conhecimento produzido e ensinado tanto na universidade quanto na escola e seus questionamentos. São questionamentos como: - Qual é significado dos conceitos específicos - da ciência, por exemplo - no curso de formação inicial? - E, para a sociedade, o que significam? É importante o professor saber como, por que e para que esse conhecimento se constitui. Ao obter respostas a esses questionamentos, o professor tem disponíveis os aportes necessários para falar aos estudantes sobre determinado conteúdo e/ou conceito. Reflexões sobre o saber docente do conhecimento é o que apresentamos neste artigo, que está fundamentado em um relato de experiência, no qual discutimos com um grupo de professoras (curso de formação continuada), que atuam na educação infantil, o conteúdo "solo". Nesta atividade fica evidente a falta de conhecimento das professoras sobre o assunto "solo", bem como a pouca reflexão sobre ele. Ao que foi possível observar, as professoras apresentam aos estudantes o conceito de "solo" de maneira acrítica, sem uma reflexão do que significam os termos científicos envolvidos no conceito.
\end{abstract}

Palavras-chaves: Ensino de Ciências. Formação de professores. Saberes docentes.

\begin{abstract}
All this knowledge must be employed in the initial training course of the teacher, as it builds the identity of future teachers. In this article we bring discussions concerning the teaching knowledge of knowledge, namely that referred to the knowledge produced and taught both at university and at school and their questions. Are questions as: - What is the meaning of specific concepts - science, for example - in the course of initial training? - And for society, what mean? Teachers important to know how, why, and what this is knowledge. To get answers to these questions, the teacher has available the contributions needed to talk to students about certain content and/or concept. Reflections on the teacher's knowledge is what we present in this article based on an experience report, in which we discussed with a group of teachers the content ground in continuing training course, who work in early childhood education, the content "soil". In this activity is evident lack of knowledge of the teachers on the subject "soil" as well as a short reflection on it. We observed that teachers show students the concept of "soil" uncritically, without reflection of the meaning of scientific terms involved in the concept.
\end{abstract}

Keywords: Science Teaching. Teacher training. Teacher's knowledge. 


\section{INTRODUÇÃO}

Ao iniciar um texto sobre formação do professor, vem, de imediato, a lembrança de Nóvo® ${ }^{1}$ e suas reflexões sobre o professor como um ser que se constitui historicamente. Para Nóvoa: "O professor é uma pessoa: e uma parte importante da pessoa é o professor" (NOVOA, 1992, p. 7).

A história de vida de cada pessoa constitui a sua profissionalização e isso se torna mais evidente quando se fala na formação do professor. Mesmo antes da entrada em um curso superior essa identidade começa a ser construída por meio das práticas vivenciadas enquanto estudante. Assim, todo percurso durante a formação escolar, desde o ingresso na infância na escola, contribui para a consolidação de uma "identidade docente". O espaço escolar fornece um arcabouço tanto ideológico como pedagógico que sustenta a construção de uma identidade única e pessoal. Ao ingressar em um curso superior, com características de formação à docência, o futuro professor se constituirá como tal, pois é nesse ambiente que ele (professor) pode reunir os elementos técnicos e teóricos para constituir-se como um profissional. É bom lembrar que essa identidade docente não é uma "vestimenta", ou algo inabalável, tampouco algo externo, mas é um processo de construção que acontece sócio-histórica e culturalmente situado.

Para Piment ${ }^{2}$ (1996), um curso de licenciatura deve desenvolver nos alunos:

\begin{abstract}
[...] conhecimentos e habilidades, atitudes e valores que lhes possibilitem, permanentemente, irem construindo seus saberes e fazeres docentes, a partir das necessidades e desafios que o ensino, como prática social, lhes coloca no cotidiano (PIMENTA 1996 p. 6).
\end{abstract}

\section{Para mesma autora,}

[...] o saber do professor se fundamenta na tríade saberes das áreas específicas, saberes pedagógicos e saberes da experiência. É na mobilização dessa tríade que os professores desenvolvem a capacidade de investigar a própria atividade e, a partir dela, constituírem e transformarem seus saberes-fazeres docentes (PIMENTA 2007 p. 8).

Complementando a ideia anterior, Veiga e Passos (2008) afirma que se constituem em saberes da docência, a experiência, o conhecimento e os saberes pedagógicos. Nesse sentido, a formação inicial refere-se à

\footnotetext{
${ }^{1}$ Professor universitário português, atualmente professor catedrático do Instituto de Educação da Universidade de Lisboa e reitor honorário da mesma universidade.

${ }^{2}$ Com formação de graduação e pós-graduação na PUC/SP e atuação nessa universidade, na USP e em outras IES do Estado de São Paulo, atua principalmente nos seguintes temas: formação de professores, didática, pedagogia e pesquisa educacional. As pesquisas mais recentes são no campo da Pedagogia Universitária e Docência no Ensino Superior. É Pesquisador $1 \mathrm{~A}$ CNPq.
}

profissionalização, mas não se resume a ela. A profissionalização caminha por um processo formativo complexo de mudança. É na formação inicial que são encontrados os saberes dos futuros professores e os saberes do currículo, prosseguindo com a reflexão crítica da prática após a formação (formação continuada). Assim, a construção da identidade docente passa por um processo complexo, processo no qual cada um se apropria dos sentidos e das percepções da sua história pessoal e profissional. Dito de outra forma, a formação do professor deve proporcionar a tomada de consciência das concepções e dos modelos pessoais e provocar a formação de uma identidade docente própria. De forma resumida, a construção docente pode ser representada de acordo com o esquema mostrado na Figura 1

Figura 1: Construção de uma identidade docente.

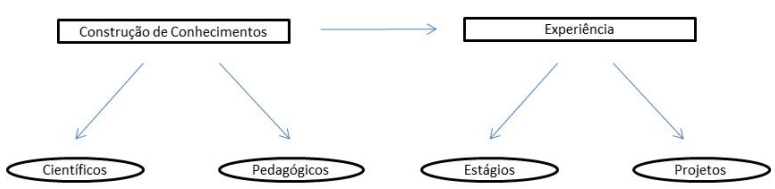

Também na construção da identidade docente e, em função das necessidades sociais, muitas propostas têm sido efetivadas no sentido de "reinventar os professores e suas práticas pedagógicas”. Para Bueno (2006), objetiva-se reinventar a profissão docente e os próprios professores, dos quais se pretende um perfil mais adequado aos novos tempos. Dessa forma espera-se que esses profissionais possam atender a três planos, com suas respectivas características:

- Plano pessoal: receptivos à diversidade, abertos a inovações, sensíveis às dificuldades dos estudantes e comprometidos com seu êxito;

- Plano intelectual: portadores de sólida formação científica e cultural, domínio da língua materna e de novas tecnologias;

- Plano profissional: capazes de articular os conteúdos curriculares de sua disciplina com vários outros conhecimentos e, ainda, trabalhar em equipe assumindo a gestão de seu próprio desenvolvimento profissional (BELO; BUENO, 2005 apud BUENO, 2006, p. 224).

Diante disso é possível perceber uma gama de conhecimentos, experiências, habilidades e características pessoais que permeiam a formação do professor. Isso torna o "ser professor" um complexo emaranhado de funções e de atitudes, complexidade que nem sempre 
pode ser atendida durante um curso de formação. Todas as características apontadas anteriormente referem-se à formação de professores de modo genérico (em todas as áreas), entretanto neste contexto há que se questionar a formação de professores para os chamados Anos Iniciais do ensino. Essa formação, em geral, se dá por meio de cursos de graduação de Pedagogia, que, por melhor que sejam seus projetos pedagógicos, dificilmente possibilitarão conhecimentos aprofundados em todas as áreas, como é o caso do Ensino de Ciências. Em geral os cursos de Pedagogia oferecem somente uma disciplina que aborda temáticas de Metodologia do Ensino de Ciências, sendo raro o curso que oferece opções de aportes conceituais sobre ciências (saberes de áreas específicas), de modo que os futuros professores, além de buscar metodologias para "ensinar ciências", tenham o domínio científico dos conceitos. É nesse sentido que este artigo se constitui.Ou seja, pretendemos aqui apresentar elementos que representam a necessidade de saberes da área das ciências (saberes do conhecimento) para que o professor possa desenvolver atividades em ensino de ciências nos Anos Iniciais da escolarização.

\section{Fundamentação}

\subsection{A FORMAÇÃO INICIAL E OS SABERES NECES- SÁRIOS}

A formação inicial de professores tem sido objeto de estudo de inúmeros trabalhos e em diversas áreas e disciplinas escolares. $\mathrm{Na}$ área das Ciências muito se tem investigado sobre o processo e a importância de formação.

Utilizando-nos dos estudos de Pimenta (2007) e dos saberes da docência de Carvalho e Gil-Pérez (2011) e as necessidades formativas dos professores, e da pesquisa de Leite (2015), que relaciona as competências da formação com dimensões de alfabetização científica, pautamos nossa discussão nos elementos necessários ao professor para que possa realizar suas atividades didáticas comprometido com o conhecimento científico.

Os saberes da docência discutidos por Pimenta (2007) são: a experiência, o conhecimento e os saberes pedagógicos, e todos eles precisam ser mobilizados no curso de formação inicial, à medida que se constrói a identidade dos futuros professores:

- Quanto à experiência, trata-se do desafio da formação inicial em colaborar no processo de deixar de ser estudante e passar a ser professor, pelo qual os licenciandos passam ao longo do curso, e ainda mais complexo devido à imagem de professor que os licenciandos já possuem ao chegarem ao curso.
- Quanto ao conhecimento, isso diz respeito aos questionamentos acerca do conhecimento, produzido e ensinado tanto na universidade como na escola. São questionamentos como: - Qual é significado dos conceitos específicos - da ciência, por exemplo - no curso de formação inicial? - E, para a sociedade, o que significam? Para a autora, também não basta produzir conhecimento, mas criar condições para essa produção, e, ainda, pensar sobre a relação entre consciência do poder e o conhecimento, na transformação social. Ou seja, é necessária uma reflexão acerca dos conhecimentos específicos de cada curso de formação inicial.

- Quanto aos saberes pedagógicos, pautam-se em saberes didáticos relacionados ao ato de ensinar. Esses saberes só podem ser desenvolvidos à medida que se conhece a realidade escolar, suas peculiaridades, suas necessidades... e a fragmentação dos conhecimentos específicos e pedagógicos - é o que mais dificulta o desenvolvimento desses saberes. Assim, no curso de formação inicial, deve-se aliar esses conhecimentos a alguma forma de pesquisa em sala de aula.

Neste trabalho nosso destaque é o saber do conhecimento, pois consideramos que, sem ele, as metodologias de ensino perdem seu significado, seu valor. Esse saber pode ser facilmente relacionado às necessidades formativas de Carvalho e Gil-Pérez (2011) e às competências da formação, nas quais, o conhecimento é o primeiro elemento a ser mencionado:

1. Conhecimento sobre os assuntos que serão ensinados;

2. Questionamento de ideias docentes de senso comum sobre os procedimentos de ensinoaprendizagem das ciências;

3. Aquisição de conhecimentos teóricos sobre a aprendizagem das ciências;

4. Análise crítica do ensino tradicional;

5. Preparação de atividades que promovam aprendizagem efetiva: aprendizagem como pesquisa;

6. Orientar o trabalho dos estudantes;

7. Saber avaliar;

8. Adquirir a formação necessária para associar ensino e pesquisa didática.

Segundo Carvalho e Gil-Pérez (2011), essas competências ou necessidades envolvem uma complexidade de relações nas quais as metodologias e a forma de avaliar, por exemplo, decorrem desse conhecimento. Dessa 

DO ENSINO FUNDAMENTAL I

forma, defendemos aqui que o professor de Ciências (ou aquele que desenvolve conteúdos de Ciências) deve, ao entrar em sala de aula, ter desenvolvido os saberes da docência, em especial o saber do conhecimento e, aliado a isso, possuir a competências da formação: conhecimento sobre os assuntos que serão ensinados, que envolvem principalmente conhecer as origens e as implicações desse conceito, as orientações CTS envolvidas, as metodologias... (CARVALHO; GIL-PÉREZ, 2011. LEITE, 2015).

E, diante disso, direcionamos nosso olhar para a formação dos professores das séries iniciais, que ministram varias áreas do conhecimento, dentre elas, Ciências. Questionamos, então: - Como professores poderão trabalhar conceitos das ciências em geral, quando esses conceitos são parciais ou inexistentes na sua formação inicial?

De acordo com as matrizes curriculares de alguns cursos de Pedagogia da região em que aconteceu esta pesquisa - são quatro universidades e seis cursos - é possível perceber que não há ampla formação na área de Ciências, o que, no nosso entendimento, prejudica o trabalho, em sala de aula, desses professores. De modo geral, é possível encontrar, na maioria dos cursos, apenas uma única disciplina sobre Metodologia do Ensino de Ciências, disciplina com o objetivo principal de propiciar discussões metodológicas e não de conceitos científicos, ou seja, não são disciplinas que tratam de conceitos relativos à Química, à Física e à Biologia. Além disso, a carga horária varia de 68 horas a 102 horas (em dois cursos). Por outro lado, há uma universidade que apresenta, em seu projeto pedagógico, além da disciplina de Metodologia do Ensino de Ciências, as disciplinas de Ecologia, de Biologia Educacional e de Teoria e Prática de Ensino de Ciências, sendo que as duas últimas são não presenciais (EaD).

\section{CONTEXTO DO TRABALHO}

Este trabalho é um relato de atividade realizada durante um curso de formação para professoras atuantes no nível fundamental de ensino de um município do estado do Paraná. São professoras envolvidas no projeto COMQUÍMICA das crianças. Esse projeto busca inserir estudantes do Ensino Fundamental em estudos de ciência, vivenciando a experiência de "ser cientista". O projeto está configurado em uma metodologia de ensino por investigação, configuração na qual são oferecidas oficinas de ciências para crianças em um laboratório no interior do NECTO (Núcleo de Ensino em Ciências de Toledo), da Universidade Estadual do Oeste do Paraná/Unioeste.
As atividades do projeto COMQUÍMICA das Crianças iniciaram no ano de 2012, ano no qual realizamos sete oficinas de outubro a dezembro com crianças do $2^{\circ}$ ao $5^{\circ}$ ano do Ensino Fundamental. Nesse período participaram das oficinas três escolas da sede do município e uma escola de distrito, por meio de agendamento prévio das escolas. No ano de 2013 seguiu-se, durante todo o ano, a oferta de oficinas às escolas por meio de agendamento prévio.

Em 2014 foi efetivada uma parceria com a Prefeitura Municipal Toledo e neste ano foram realizadas 77 oficinas, com participação de mais de 500 estudantes do turno integral, com faixa etária de 3 a 9 anos, cursando do Pré I ao $5^{\circ}$ ano do Ensino Fundamental. A partir deste ano, as atividades do COMQUIMICA passaram a ser periódicas. Assim, as crianças são recebidas no Laboratório COMQUIMICA em dois horários semanais, sendo um matutino e um vespertino, de modo a atender aos horários e às necessidades advindas das escolas municipais. As crianças vêm até a universidade junto com seus professores, que também participam das oficinas, estas com duração de aproximadamente uma a duas horas.

No ano de 2015 a parceria com a Prefeitura/Secretaria de Educação de Toledo foi mantida e as atividades do COMQUIMICA tomam forma e corpo para se consolidar como um espaço permanente de extensão universitária e de formação de uma cultura científica.

Também a partir de 2015 passamos a realizar atividades de formação para os professores envolvidos, para que compreendam e também realizem atividades semelhantes às nossas na escola.

\section{APORTES METODOLÓGICOS}

Este trabalho é um relato de experiência de um curso de formação no qual utilizamos características de uma pesquisa qualitativa descritiva. A ideia central é apresentar aspectos para uma reflexão sobre a formação do professor que atua nos Anos Iniciais de ensino, considerando as aulas de Ciências.

\subsection{Os Participantes: perfil geral}

O encontro de formação contou com a participação de 42 professoras que atuam na área de Ciências das escolas municipais da cidade de Toledo. O curso de formação foi realizado no NECTO, dia 9 de fevereiro de 2015, durante o espaço destinado para reflexão pedagógica das professoras. A formação dessas professoras é 
diversa, como pode ser observado no gráfico da Figura 2

Figura 2: Formação das professoras participantes da oficina.

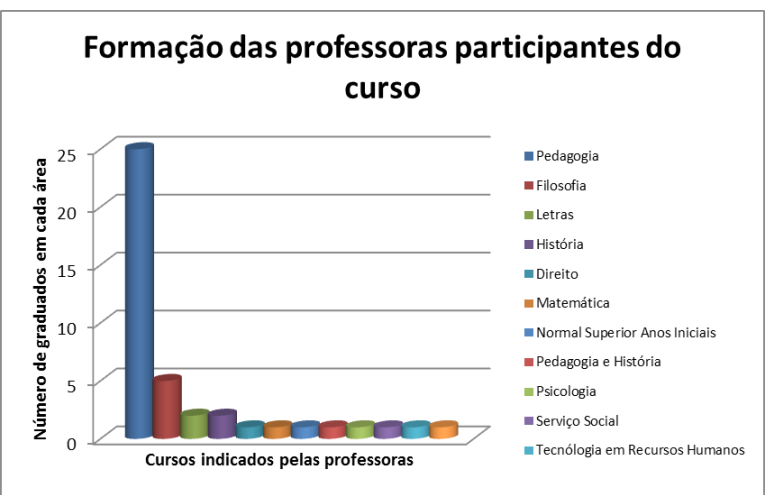

É facilmente observável que mais da metade do grupo possui formação em Pedagogia, mas também outro ponto de destaque é a variedade de cursos de formação que esse grupo apresenta, pois são apenas seis (6) licenciaturas em uma lista de 11 cursos diferentes. Ou seja, em uma etapa tão importante para construção de conceitos pelos estudantes a formação adequada dos profissionais não atende ao ideal, pois deveria centrarse em cursos de Pedagogia e Normal Superior, e neles, a formação em Ensino de Ciências (e outras áreas específicas) deveria ser melhor contemplada.

Quanto à pós-graduação, 29 professoras possuem especialização, entretanto não listaremos o vasto número de cursos indicados, mas destacamos que os mais citados foram: Psicopedagogia (11 indicações), Educação Especial (7 indicações), e Gestão Pública ou Educacional ( 2 indicações), sendo que alguns possuem mais de uma especialização.

Quanto ao tempo de serviço no magistério, o grupo também era bastante diversificado, conforme se pode melhor visualizar no Quadro 1 .

Quadro 1: Tempo de serviço das professoras

\begin{tabular}{cc}
\hline Número de Professoras & $\begin{array}{c}\text { Tempo de magistério } \\
\text { (anos) }\end{array}$ \\
\hline 10 & $0-5$ \\
17 & $6-10$ \\
6 & $11-20$ \\
6 & Mais de 21 \\
3 & Não responderam \\
\hline
\end{tabular}

Conforme apresentado no quadro anterior, é possível observar que cerca de $25 \%$ das professoras se encontram-se em início de carreira (até 5 anos de atuação nas escolas). A maioria das professoras (17) exerce o magistério já por um período de 6 a 10 anos; outras seis (6) estão na metade da carreira profissional. Seis professoras encontram-se na final de carreira, considerando que a aposentadoria pode ocorrer aos 25 anos de exercício da profissão.

\subsection{Descrição da atividade}

Foram realizadas atividades teórico-práticas tendo como pressuposto o Ensino por Investigação. Para a condução das atividades utilizamos o conteúdo escolar "solo", como já antes informado. O curso foi realizado em um período de quatro (4) horas, no Laboratório COMQUÍMICA, no Núcleo de Ensino em Ciências de Toledo/Unioeste. As etapas do curso foram: (i) envio do texto aos professores cursistas previamente e discussão do texto em conjunto; (ii) apresentação e discussão do conteúdo "solo"; (iii) observação de amostras de solo de diversos locais; e (iv) atividade experimental sobre o assunto "solo" presente no Manual COMQUÍMICA (CUNHA; PERES; STANZANI, 2014).

\section{Etapa 1}

O encontro iniciou com a discussão teórica do texto "O ensino de Ciências e a proposição de sequências de ensino investigativas", da autora Anna Maria Pessoa de Carvalho, texto o qual foi fornecido pelas ministrantes, via Secretaria de Educação do município de Toledo, para que fosse realizada a leitura prévia pelos professores participantes. Entretanto, ao serem questionados sobre quem fez a leitura prévia do texto, apenas uma pequeníssima parcela do grupo havia realizado (em torno de cinco professoras), contudo as professoras haviam levado um cópia do texto para o encontro.

Assim, procedemos à discussão de alguns pontos relevantes apresentados pela autora do texto, especialmente no que se refere aos aspectos teóricos da importância de se considerar os conhecimentos prévios das crianças (Piaget) e do trabalho cooperativo (ZDP/Vigotski), quando se pretende realizar um ensino por investigação. Também salientamos a importância de propor um problema inicial que possa conduzir a atividade, a forma como o professor deve proceder na abordagem do Ensino por Investigação e as etapas da SEI (Sequência de Ensino Investigativa). A partir dessa introdução teórica passamos a uma fase de reflexão de um conceito/conteúdo que é normalmente desenvolvido 
pelos professores na sala de aula. O conteúdo selecionado para essa atividade foi solo.

\section{Etapa 2}

Para conduzir a discussão, propusemos a reflexão de alguns elementos que constituem ou podem constituir o conhecimento escolar, fazendo a leitura em voz alta do conceito formal (disponível em materiais didáticos) solo. Com o conceito apresentado na tela, tentamos identificar o entendimento das professoras acerca das palavras que constituem esse conceito, por meio de um trecho retirado da web: "O solo nada mais é do que o resultado da ação conjunta de agentes externos (como chuva, vento, umidade etc.) sobre restos minerais, porém enriquecidos com matéria orgânica."Sem a presença de matéria orgânica não há a formação de solo, tratando-se somente de minerais não consolida$d o s^{3}$ (grifos nossos que representam a ênfase dada pelo leitor no momento da exposição do conceito).

Após a apresentação e discussão do conceito, apresentamos às professoras algumas "palavras", palavras essas com que elas deveriam expressar suas representações/percepções. Iniciamos pela palavra TERRA e, posteriormente, SOLO. A partir da reflexão sobre as representações e significados dessas duas palavras, apresentamos três imagens que faziam referência ao tema solo.

Na Figura 3 (a) é um desenho de solo com algumas camadas internas. Na Figura 3 (b), uma fotografia da superfície de solo e a na Figura 3 (c), uma fotografia de um corte de solo no qual é possível ver sua superfície coberta por vegetação e a parte logo abaixo da vegetação (interna).

Também é interessante mencionar o que consta no livro didático de Ciências utilizado no municípid ${ }^{4} \mathrm{O}$ conteúdo solo aparece em todos os volumes e o que muda é a abordagem do tema. Uma análise simples dos livros é mostrada no Quadro 2

A partir do Quadro 2 é possível ponderar sobre a sistematização do conteúdo "solo". Apesar de os autores respeitarem o nível cognitivo dos estudantes, ainda assim esse conteúdo se apresenta de forma simplificada e informativa, pois o conhecimento científico fica em segundo plano, não sendo esse o principal objetivo.

\footnotetext{
${ }^{3}$ Fonte: $\quad<$ http://www.colegioweb.com.br/trabalhos-escolares/ 2-ano/a-formacao-do-solo.html\#ixzz3Qj4s2bet>

${ }^{4}$ PESSOAA, Karina Alessandra. A escola é nossa: ciências. $2^{\circ}$ $3^{\circ}, 4^{\circ}$ e $5^{\circ}$ ano. São Paulo: Scipione, 2011 (Coleção "A Escola é Nossa").
}

Figura 3: Tipos de solo.

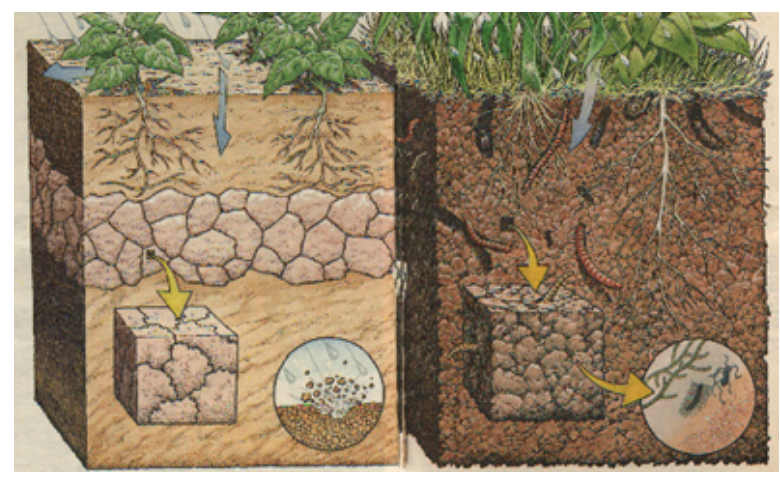

(a)

Fonte: http://estagiositiodosherdeiros.blogspot. com.br/p/analise-de-solo.html

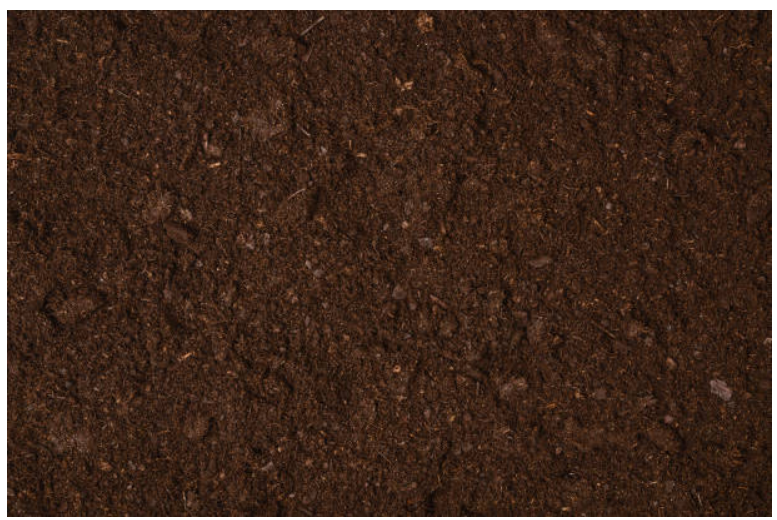

(b)

Fonte: http:// https://media.istockphoto.com/photos/fertile-gardensoil-texture-background-top-view-picture

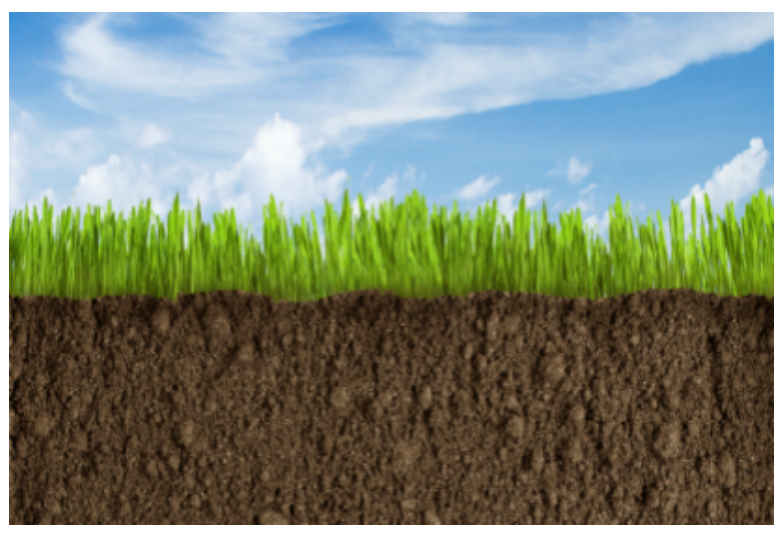

(c)

Fonte:

http://www.expedicaooriente.com.br/blog/terra-firme-e-saudavel/

Salientamos, contudo, que a abordagem proposta pelos autores inclui problematização, experimentos, ques- 


\begin{tabular}{|c|c|}
\hline Ano/série do livro & Descrição do conteúdo no livro \\
\hline $2^{\circ}$ ano & $\begin{array}{l}\text { Ausência de definição de solo e indicação da importância do solo para os seres vivos. } \\
\text { "O solo é muito importante para os seres vivos. } \\
\text { O ser humano cultiva no solo plantas que servem como alimento, além de outras plantas } \\
\text { utilizadas em diferentes situações. } \\
\text { É no solo que muitos vegetais se fixam. } \\
\text { Existem animais que vivem no interior do solo ou moram em tocas, no interior do solo" } \\
\text { (PESSÔA, 2011, p. 45). }\end{array}$ \\
\hline $3^{\circ}$ ano & $\begin{array}{l}\text { Indicação da importância e da composição de solo. } \\
\text { "O solo é um componente do ambiente muito importante para os seres vivos. } \\
\text { É no solo que: } \\
\text { - muitos vegetais se fixam e dele obtém água e sais minerais; } \\
\text { - as pessoas e outros animais vivem e constroem seus abrigos; } \\
\text { - o ser humano cultiva vegetais, cria animais e faz construções" (PESSÔA, 2011, p. 23). }\end{array}$ \\
\hline $4^{\circ}$ ano & $\begin{array}{l}\text { Trata da definição, formação, componentes do solo, definição de matéria orgânica e } \\
\text { utilização do solo pelo ser humano. Também apresenta a noção se subsolo. } \\
\text { "O solo é a camada da superfície terrestre popularmente chamada chão, terra. É sobre } \\
\text { o solo que caminhamos, construímos nossa casa, estradas, entre outras atividades. } \\
\text { Geralmente, o solo é composto de: } \\
\text { - pedaços de rochas que sofreram desgaste; } \\
\text { - restos de vegetais e animais em decomposição, ou seja, apodrecidos. } \\
\text { No solo também podem ser encontrados ar, água e alguns seres vivos. } \\
\text { O subsolo é a camada da superfície da Terra localizada logo abaixo do solo. } \\
\text { No subsolo, podem ser encontrados água, petróleo, gás natural, ouro, ferro, } \\
\text { prata, entre outros" (PESSÔA, 2011, p. } 107, \text { negrito no original). }\end{array}$ \\
\hline $5^{\circ}$ ano & $\begin{array}{l}\text { Trata da poluição solo. } \\
\text { "A poluição do solo, geralmente, é causada pelo depósito inadequado de lixo } \\
\text { pelo derramamento de substâncias químicas sobre o solo" (PESSÔA, 2011, p. 142). " }\end{array}$ \\
\hline
\end{tabular}

tões socioambientais, entre outros, cabendo ao professor conduzir essas atividades de forma adequada.

\section{Etapa 3}

A etapa seguinte foi constituída pela observação de amostras de solo contidas em pequenos frascos de vidro. Essas amostras foram coletadas em diversos locais (cidades diferentes) e que fazem parte de uma coleção pertencente ao acervo do NECTO (Núcleo de Ensino em Ciências de Toledo). As amostras são apresentadas na Figura 4

\section{Etapa 4}

Nessa etapa, as professoras coletaram amostras de solo no pátio da universidade (local da realização do curso), sendo cada amostra observada por meio de uma
Figura 4: Coleção de amostras de solo.

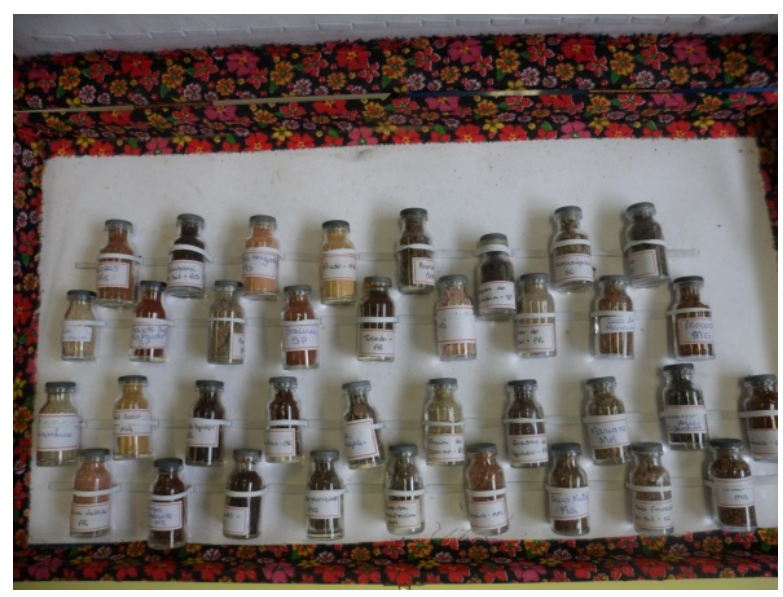

lupa de mão e, após, realizamos um teste de identifica- 
ção de carbonatos, quando na presença de ácido (vinagre). Aqui é importante salientar a sequência de apresentação para o conteúdo de solo: (i) conceito, (ii) palavra, (iii) imagem, (iv) amostra e (v) manipulação. Essa sequência de apresentação teve a finalidade de mostrar às professoras que os processos de produção de significados por parte das crianças são mais produtivos quando realizados por meio da manipulação direta com o objeto de estudo, do que com a apresentação do conceito, da imagem ou da palavra somente. Nesse sentido, o processo de manipulação com o objeto de estudo é fundamental para o entendimento de um conceito ou para a apropriação de um determinado conteúdo.

\section{DISCUSSÃO DOS RESULTADOS}

\subsection{As atividades: o que dizem as professoras}

Então, como dito acima, apresentamos o conceito de solo aos professores: "O solo nada mais é do que o resultado da ação conjunta de agentes externos (como chuva, vento, umidade etc.) sobre restos minerais, porém enriquecidos com matéria orgânica". Foi então ressaltado que o conceito inicia com a afirmação de que solo "nada mais é", expressão essa que dá aparência de que esse conceito é de fácil compreensão, não demandando interpretações mais profundas. Quando questionamos as professoras sobre a compreensão do referido conceito, elas se posicionaram concordando que o conceito era simples e de fácil entendimento.

Assim, por meio da ênfase na entonação vocal, destacamos elementos que, para nós (ministrantes), não nos pareciam de fácil compreensão por parte das professoras. Nesse sentido, o que seria o resultado da "ação conjunta", expressão citada no conceito? Todos esses agentes (chuva, vento, unidade) devem estar presentes ao mesmo tempo? Diante dessa indagação, os professores não souberam nos dizer se essa "ação conjunta" deve ser realmente "conjunta" ou se a presença de apenas alguns desses agentes externos pode formar o solo. A partir desse momento as professoras começam a refletir sobre os termos presentes no conceito de solo apresentado.

Seguindo a discussão, frisamos as palavras "restos de minerais" e perguntamos o que seriam estes minerais!? As respostas foram: ferro, ouro, cobre, entre outros. Então perguntamos se esses "minerais" estão presentes no solo? A resposta foi que em alguns solos eles devem se fazer presentes ou, como citou uma professora: "- Ah! Na minha casa não tem solo com ouro!". Diante desse questionamento, cabe afirmar que nenhuma das professoras conseguiu conceituar, descre- ver ou exemplificar minerais.

Continuando... perguntamos: - E matéria orgânica, o que é? A resposta foi: "Orgânica vem de seres vivos". Então perguntamos se, no interior do solo, correm seres vivos? A resposta: "Seres vivos que já foram vivos, que morreram". Perguntamos se os plásticos são matéria orgânica. A resposta foi: - Não! Assim, perguntamos: Por que não é? Resposta: "Porque não se decompõe". Nesse momento uma das ministrantes diz: - Se decompõe, sim, mas leva tempo. Outra professora diz que o termo orgânica remete aos estudos realizados no seu ensino médio, mas disso só consegue lembrar das cadeias carbônicas e sua classificação. Aqui aparece bem presente a falta de um conceito mais elaborado sobre "matéria orgânica" e o pouco conhecimento sobre o assunto. Também há aspectos relativos à teoria da força vital.

Percebemos aqui as ideias simplistas com relação ao termo orgânico, sendo entendido como vivo ou natural. Essa ideia se baseia - mesmo que inconscientemente na teoria da força vital, que Berzélius propôs em 1807, teoria segundo a qual se acreditava que as substâncias derivadas de organismos vivos continham uma força vital (essência da vida) e, dessa forma, foram chamadas orgânicas. Já as substâncias que não apresentavam essa força vital e eram derivadas dos minerais foram denominadas de inorgânicas. Hoje essa ideia não é mais aceita e moléculas orgânicas podem tanto ser obtidas na natureza quanto sintetizadas em laboratório (BRUICE) 2006).

É importante destacar aqui, antes de seguirmos com a ordem da atividade, que essas ideias simplistas são repassadas aos estudantes por esses professores, ou seja, os significados dos conceitos dos estudantes são construídos por meio do entendimento dos professores, entendimento que, de modo geral, é superficial ou inexistente. Se o professor não tem clareza para si os conceitos que precisa ensinar, então ele o faz com base no conhecimento restrito que possui, e assim os estudantes têm contato somente com esse conhecimento incompleto.

Todos esses questionamentos levaram as professoras a repensarem as suas respostas (instabilidade/insegurança), pois perceberam que aquele conceito aparentemente simples e fácil apresentava elementos que não são compreendidos por elas. Mesmo diante dessa aparente dificuldade, as professoras continuaram participando da discussão, respondendo a novos questionamentos.

Continuamos a discussão sobre o conceito apresentado, no qual temos: "Sem a presença de matéria or- 
gânica não há a formação de solo, tratando-se somente de minerais não consolidados." Nessa parte salientamos a referência a "minerais não consolidados". O que seriam então estes minerais não consolidados? Nesse momento houve um silêncio geral e nenhuma professora se arriscou a emitir uma definição. Apenas falas do tipo: "Não sabemos nem o que são minerais, imagina minerais não consolidados...", "É. Percebemos que não sabemos o que significa esse conceito". Perguntamos se era esse mesmo conceito que elas apresentavam às crianças quando traziam para sala de aula o tema solo. A resposta foi afirmativa.

Aqui cabe mencionar a primeira necessidade formativa discutida por Carvalho e Gil-Pérez (2011), Leite (2015). A de que o professor de Ciências precisa conhecer o conteúdo que ministra. Sem isso, como pensar em metodologias para ensinar os conceitos? É necessário saber sobre o que se ensina, mas, como já mencionamos acima, não se trata apenas de saber o conceito puro. É necessário também pensar no que implica tal conhecimento:

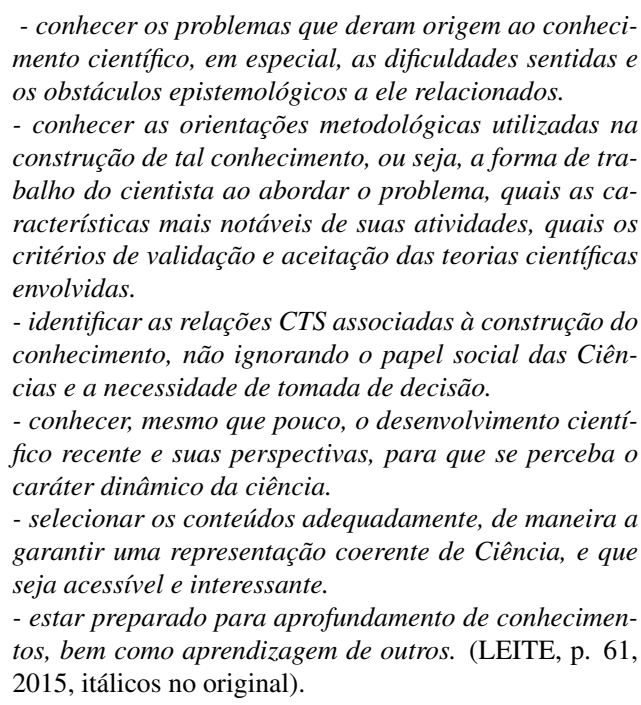

Torna-se importante relacionar também ao saber do conhecimento de Pimenta (2007), e os questionamentos acerca da importância do conhecimento. Ou seja, tratase de profundo conhecimento sobre o que ensinar, envolvendo tanto a seleção dos conteúdos e sua importância na sociedade quanto as preocupações sobre as metodologias de ensino, e, nesse caso, também é possível refletir sobre a didática das ciências, que só toma corpo a partir do momento em que a resposta a o que ensinar se constrói.

Passamos, então, para a apresentação das palavras e ao entendimento do que as professoras tinham como representação para palavra terra. Uma professora cita que terra lembra planeta (Terra), outra lembra superfície, para outra lembra chão.

Seguimos apresentando a palavra solo, a partir da qual as professores fazem referência à Terra como planeta, e à terra como chão. Discutimos um pouco essa representação e o significado cotidiano do uso da palavra terra como sinônimo de solo. As observações foram no sentido de que a palavra solo não faz parte do nosso cotidiano, mas terra, sim, sendo utilizada de modo indiscriminado, dificultando a compreensão do seu significado.

Após a discussão das palavras terra e solo, partimos para a apresentação das figuras que fazem referência a solo.

Em relação à primeira imagem (Figura $3(\mathrm{a})$ ), as professoras mencionam que é possível observar "matéria orgânica", tipos de solo como arenoso (por conta da cor) e argiloso. Elas salientam que a matéria orgânica pode ser observada nas raízes de grama que estão na imagem. Também visualizaram as gotículas de chuva estas pouco perceptíveis na imagem.

A segunda imagem (Figura 3 b)), representada por uma fotografia de uma superfície de solo, foi descrita como algo áspero, poderia ser uma lixa, café, asfalto.

$\mathrm{Na}$ terceira imagem (Figura 3 (c)), as professoras citam: matéria orgânica, húmus, umidade.

Perguntamos o que é húmus? Uma professora respondeu que é o que a minhoca produz, algo como "o 'cocô' da minhoca", pois é possível comprar o "húmus de minhoca". Alguns outros professores falam sobre a compra de húmus em casas especializadas.

Na etapa 3 apresentamos às professoras as amostras de solo em frascos de vidro, o que causou grande curiosidade, especialmente pela origem de algumas amostras, de várias localidades do país.

Solicitamos às professoras que listassem algumas características do material observado. As professoras observaram em conjunto as amostras e citaram: a cor diferente de cada amostra, o tipo de grânulos do solo e a aparência seca dos solos.

A última etapa (Etapa 4) da atividade foi a coleta de uma amostra de solo no pátio da universidade. Para as professoras foi fornecido um pote plástico e uma colher de metal. As professoras coletaram suas amostras e as colocaram em placas de Petri para sua observação com uma lupa de mão. Essa atividade possibilitou que elas observassem as partículas que formam o solo, dentre elas pequeníssimas partículas que possuem brilho, que foram identificadas por elas como "minerais".

Solicitamos que as professoras dividissem suas 
amostras em duas partes e seguimos a atividade acrescentando em uma das amostras uma pequena porção de ácido acético (utilizamos vinagre). Ao observarem a amostra de solo com vinagre, as professoras esperavam que ocorresse algum tipo de reação, com alguma mudança nos aspectos visuais do solo. Entretanto a adição de vinagre no solo tem a finalidade de identificar a presença de carbonatos, o que só é possível em alguns tipos de solo, ou solos tratados com calcário, por exemplo. Assim, na outra parte da amostra, acrescentamos um pouco de calcário, sem que fosse dito às professoras que se tratava dessa substância.

Após acrescentar o calcário também acrescentamos um pouco de vinagre, que reagiu produzindo bolhas de gás. Ao observar a formação do gás, imediatamente uma professora diz "Nossa! Está fervendo!". Questionamos: Fervendo? Tem fonte de aquecimento para ferver? A resposta foi negativa e originou a reformulação de sua expressão e então a professora passou a dizer: "Está saindo bolhas". Perguntamos o que seriam essas bolhas? Uma professora diz que poderia ser "oxigênio", o que logo foi contrariado pela colega, que disse: "Não pode ser oxigênio, pois oxigênio só se produz na fotossíntese". Repetimos para todo o grupo as falas dessas duas professoras e continuamos perguntando: $\mathrm{O}$ que são as bolhas de gás formadas no solo com vinagre? Outra professora disse que a formação de bolhas remete ao que acontece quando se coloca água oxigenada sobre um ferimento. Perguntamos então o que é água oxigenada. A resposta foi: "Tem oxigênio". Então explicamos brevemente o que acontece com a água oxigenada ao entrar em contato com um ferimento.

Apesar de as professoras estarem observando e levantando hipóteses sobre qual seria o gás produzido, nenhuma delas havia sugerido que poderia ser gás carbônico. Então mostramos uma garrafinha de água mineral com gás e perguntamos: Que gás é adicionado à água ou ao refrigerante? Nenhuma das professoras soube responder. Então voltamos à questão da reação do solo tratado com vinagre. Uma professora citou que isso acontece também com o antiácido quando colocado em água, afirmando que reage com a água. Outra professora fala que, quando se coloca bicarbonato na água com ácido (por exemplo, em uma limonada), produz também uma efervescência.

A partir de toda essa discussão e das hipóteses levantadas pelas professoras (ver referências - mesmo que gerais - sobre o gás em questão, o gás carbônico), revelamos que havíamos adicionado calcário à amostra de solo coletado e em análise. Mencionamos que, na composição do calcário, temos os carbonatos. Frisa- mos a palavra carbonato de modo que as professoras percebessem que a palavra provém de carbono, o que realmente aconteceu. Caminhamos no sentido de que, se há carbonato na composição do calcário, este deveria ter reagido com o vinagre e produzido um gás que deve apresentar o elemento carbono. Uma professora, então sugere que esse gás deveria ser o gás carbônico. Concordamos com resposta da professora e complementamos que o gás do refrigerante ou aquele produzido pelo antiácido também é gás carbônico.

Nesta etapa do curso fica evidente a falta de conhecimento das professoras sobre o conceito de reação química, ou de substâncias presentes no seu cotidiano, como o gás presente no refrigerante e na água mineral.

Embora nossa discussão tenha sido detalhada para cada uma das etapas dessa atividade, podemos observar que as professoras participantes do curso possuem profundas dificuldades relacionadas aos assuntos da ciência, aos conceitos científicos que necessitam ensinar nas suas aulas. Ou seja, há um problema de formação dessas professoras, pois elas não dispõem do conhecimento que precisam transmitir.

\section{ALGUMAS CONSIDERAÇÕES}

Diante dos relatos das professoras, na presente atividade podemos voltar à nossa questão inicial, qual seja: - Como professores poderão trabalhar conceitos da ciência com uma formação limitada? Neste relato de experiência, essa questão fica em destaque, pois durante todo curso fica evidenciada a deficiência conceitual das professoras. É possível constatar que há sérios problemas no que se refere a aspectos conceituais de um conteúdo muito trabalhado com as crianças no Ensino Fundamental - o solo.

As professoras, aqui representadas, demonstram a falta de conhecimento sobre o assunto em questão, bem como a falta de reflexão sobre ele. Ao que foi possível observar, as professoras apresentam aos estudantes o conceito de solo de maneira acrítica, sem uma reflexão do que significam os termos científicos envolvidos no conceito. O conceito é uma memorização e repetição daquilo que os materiais didáticos disponíveis trazem. Essa memorização inicia no professor e terá reflexos na consolidação do conceito por parte dos estudantes. Assim, questiona-se: - Como poderá o professor "ensinar" um conceito que nem mesmo ele estudou e compreendeu efetivamente? Como esse professor poderá propor metodologias como, por exemplo, o Ensino por Investigação, sem uma compreensão adequada do que ele representa? Essas e muitas outras questões poderiam ser feitas considerando apenas um aspecto da formação do 
professor, a necessidade formativa discutida por Carvalho e Gil-Pérez (2011), Leite (2015): o professor de Ciências precisa conhecer o conteúdo que ministra. Nesse sentido, é relevante um aprofundamento teórico sobre as ciências e seu ensino, que deveria ou poderia ser realizada no seu curso de formação inicial.

Em geral, os cursos de formação inicial de professores de Ensino Fundamental tratam muito mais da formação do professor em relação a sua competência pedagógica do que conceitual e esse fato tem ocasionado lacunas conceituais graves, como a que foi mencionada aqui. Nesse sentido, é importante que os cursos de formação inicial e de formação posterior (como as especializações) discutam também os aspectos conceituais do conhecimento, pois, sem esses conceitos científicos, não será possível a formação em nível adequado de estudantes na área de Ensino de Ciências.

\section{REFERÊNCIAS}

BRUICE, P. Y. Química orgânica. 4. ed. São Paulo: Pearson Prentice Hall, 2006. v. 1.

BUENO, B. O. É possível reinventar os professores? a "escrita de memórias" em um curso espacial de formação de professores. In: SOUZA, E. C.; ABRAHAO, M. H. M. B. (Ed.). Tempos, narrativas e ficções: a invenção de si. Porto Alegre: EDIPUCRS, 2006. v. 1.

CARVALHO, A. M. P.; GIL-PÉREZ, D. Formação de professores de ciências: tendências e inovações. 10. ed. São Paulo: Cortez, 2011.

CUNHA, M. B. da; PERES, O. M. R.; STANZANI, E. de L. Manual comquímica das crianças: oficinas para experimentação investigativa destinadas. Toledo: Gráfica Joel, 2014. Disponível em: <https://www5.unioeste.br/portalunioeste/toledo/ nucleos-toledo/necto/material-didatico-necto $>$. Acesso em: 05 maio 2020

LEITE, R. F. Dimensões da alfabetização científica na formação inicial de professores de química. Tese (outorado em Educação para a Ciência e a Matemática) - Centro de Ciências Exatas, Universidade Estadual de Maringá, Maringá, 2015. 235 f.

NOVOA, A. Vida de professores. 1. ed. Portugal: Porto Editora, 1992.

PIMENTA, S. G. Formação de professores: saberes da docência e identidade do professor. Revista da Faculdade de Educação, v. 22, n. 2, p. 72-89, 1996.
PIMENTA, S. G. Formação de professores: identidade e saberes da docência. In: PIMENTA, S. G. (Ed.).

Saberes pedagógicos e atividade docente. São Paulo: Cortez, 2007.

VEIGA, I.; PASSOS, A. Profissão docente: novos sentidos, novas perspectivas. 1. ed. Campinas: Papirus, 2008. 